\title{
The use of modern bactericidal UV irradiators in poultry houses for broilers
}

\author{
Irina P. Saleeva ${ }^{1}$, Evgeniya V. Zhuravchuk ${ }^{1, *}$, Vitaly Yu. Morozov², Roman O. Kolesnikov², \\ Margarita S. Kolesnikova ${ }^{2}$, and Anna A. Zaremskaya ${ }^{1}$ \\ ${ }^{1}$ Federal Scientific Center “All-Russian Research and Technological Institute of Poultry” of Russian \\ Academy of Sciences, Department of the Technology of Poultry Production, 141311, Sergiev Posad, \\ Russia \\ ${ }^{2}$ Saint-Petersburg State Agrarian University, Department of Large Livestock Breeding, 196601, \\ Saint-Petersburg, Pushkin, Russia
}

\begin{abstract}
Increased microbial load in the air of poultry houses for broilers is a serious and urgent problem since it leads to the decreased productivity in broilers and pollution of the open air in the farms and adjacent territories. The use of modern ultraviolet (UV) irradiators for populated poultry houses with floor housing of broilers is proposed as the solution of the problem. A regime for the use of upper-room UV irradiators with amalgam ozone-free bactericidal lamps was developed. The device "Recirculator of ventilated air" (RVA) was developed for the regime of air sanitation using closed UV irradiation. Disinfection of air within the poultry houses with the use of these techniques improved live bodyweight and decreased mortality level in broilers.
\end{abstract}

\section{Introduction}

High concentration of poultry on relatively small production areas and high flock density in conditions of the commercial production is known to increase microbial loads in the air and on the surfaces within the poultry houses and to pollute the air on the farms and adjacent territories. Systems of ventilation in poultry houses are emitting substantial daily volumes of bioaerosol, dust, and harmful gases (ammonia, carbon dioxide). These negative impacts on the air quality can in turn deteriorate productivity in poultry and health of the farm personnel and habitants of the adjacent residential zones [1-4].

The bioaerosols from poultry houses can contain microbial species from geni Pseudomonas, Bacillus, Corynebacterium, Pasteurella, Vibrio, Enterobacter, Salmonella, Brucella, Leptospira, Haemophilus, Mycoplasma, Yersinia, Staphyloccocus, Streptococcus, Micrococcus, Pantoea, Sarcina, etc. In the air of poultry houses 6 Gram-positive, 31 Gramnegative, and 11 fungal species were totally identified; many of these species are hazardous pathogens of poultry and immunocompromised humans $[5,6]$.

Concentrations of total aerobic mesophilic bacterial species within the air of poultry houses can reportedly vary from $4.74 \times 10^{4}$ to $1.89 \times 10^{8} \mathrm{CFU} / \mathrm{m}^{3}$; the concentration range for

\footnotetext{
* Corresponding author: evgeniy_20.02@mail.ru
} 
Gram-positive species is $3.78 \times 10^{4}$ to $6.65 \times 10^{7}$, for Gram-negative $4.33 \times 10^{2}$ to $4.29 \times 10^{6}$ $\mathrm{CFU} / \mathrm{m}^{3}$. Concentration of the Enterococci can vary from $1.53 \times 10^{4}$ to $1.09 \times 10^{7} \mathrm{CFU} / \mathrm{m}^{3}$ [7].

The microbial load in the air is also an important indicator of the potential epizootic hazard in a poultry farm since pathogens can be rapidly disseminated through the air and result in the outbreaks of airborne diseases in all the neighboring flocks.

The main sources of the infections are the contaminated and/or ill birds releasing the pathogens into the air medium with subsequent dissemination by air streams and airborne contamination of previously healthy birds within the same poultry house [8]. Then pathogens can enter the outer air via the ventilation system and spread on the significant areas; e.g. viruses of Newcastle disease, chicken infectious bronchitis, infectious laryngotracheitis can spread with the dust in the zone with $5 \mathrm{~km}$ radius $[9,10]$.

The sanitation of the air medium within the poultry houses is therefore an extremely important task, the disease preventing actions and disinfectants which could be applied in the populated poultry houses being especially effective from the economical standpoint.

One of these methods is the bactericidal ultraviolet (UV) irradiation of the air capable of the elimination of viruses, bacteria, and fungi [11]. The bactericidal mechanism of the UV irradiation involves the absorption of UV photons by DNA and RNA of microbial cells leading to their restructuring and resulting loss of the reproducibility by the irradiated cells.

The UV irradiation of air in populated poultry houses requires the avoidance of the direct UV irradiation of poultry itself to prevent the detrimental effects on the latter (erythemas, corneal burns, etc.). The safest for poultry are methods of closed irradiation (when the air is forcedly pumping through the closed box with UV lamp) and upper-room irradiation (when the stream of UV radiation is directed to the upper part of the poultry house and only reflected UV reaches the poultry itself).

The aim of the study presented was the adjustment of these two methods of air disinfection by UV-irradiators in the populated poultry houses for broilers and investigation of their effects on the efficiency of air disinfection and on the productive performance in broilers.

\section{Materials and methods}

Two techniques of air disinfection by modern UV-irradiators in the populated poultry houses for floor-housed broilers were studied and advanced: upper-room method (Trial 1) and method of closed UV irradiation (Trial 2). Poultry houses with standard technology of broiler rearing (without UV irradiation of the air) were used as the control treatments.

In Trial 1 the bactericidal UV-irradiator (300 W) with ozone-free amalgam lamp ALC 300/144-U2 (87 W of bactericidal UV radiation at $254 \mathrm{~nm}$ ) was used. The irradiator was set in $2 \mathrm{~m}$ above the floor and the radiation was oriented to the ceiling of the poultry house (upper-room method). The UV radiation density at the level of poultry was $11.4 \mathrm{~mW} / \mathrm{m}^{2}$, average radiation density for the entire space of the house $287.7 \mathrm{~mW} / \mathrm{m}^{2}$. The vertical air flows within the houses constantly transferred the microorganisms to be eliminated from the zone with low UV exposure (the level of poultry) to the zone with high exposure (upper part).

The following intermittent irradiation regime was applied: since 1 to 7 days of broilers' age -1 hour 6 times a day; since 8 to 28 days of age -10 minutes 12 times a day (or each 2 hours); since 29 days of age to the slaughter - 15 minutes 12 times a day (or each 2 hours). The exposure periods was enlarged from 10 to 15 minutes since 29 days of age in relation to higher dust concentration in the air and dusting of the lamp resulting in the decrease in its radiation density by $30 \%$. The intermittent irradiation regime in the poultry house was coordinated with the intermittent lighting regime; irradiations were performed during the light phases of the latter. 
In Trial 2 the new device "Recirculator of ventilated air" (RVA) developed by the authors was used; the device can be applied in the presence of poultry and farm personnel, it does not compromise the technological processes within the poultry house. The air was disinfected by the RVA throughout the light phases of the day in the regime 1 hour of running and 2 hours of break.

The body of RVA (Fig. 1) is equipped with ventilator for air pumping and bactericidal UV lamps (Philips TUV PL-L 95W/4P HO 1CT) running along it. On the output of the UV camera the hydraulic camera is situated involving hydraulic collector, spraying nozzles, drainage chute, water filter, water pump, and return tube. Ventilator and air filter are connected to the flat end of the body.

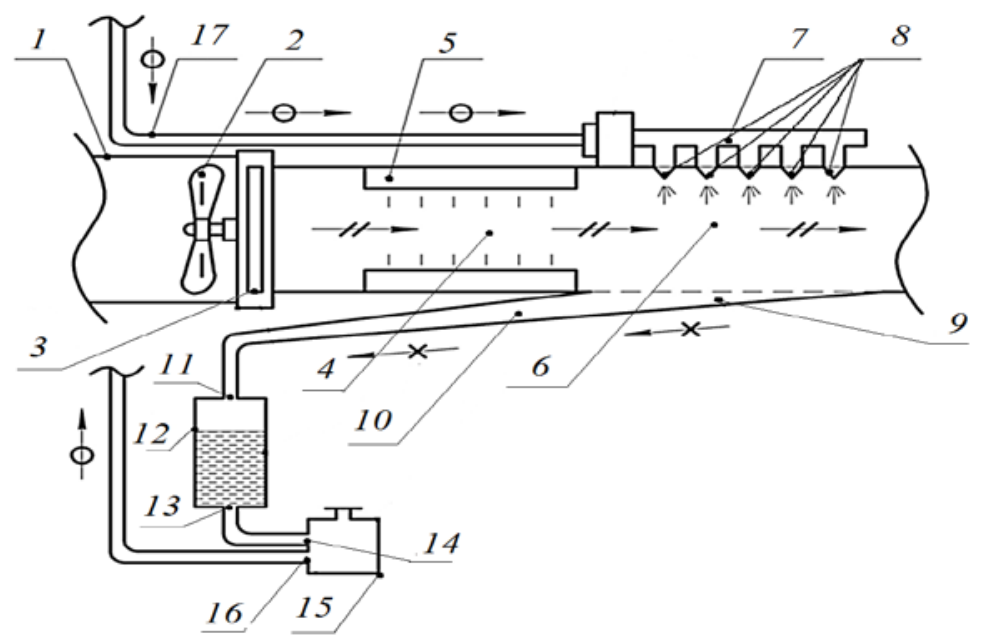

1 - body, 2 - ventilator, 3 - air filter, 4 - UV camera, 5 - bactericidal UV lamps, 6 - hydraulic camera, 7 - hydraulic collector, 8 - spraying nozzles, 9 - drainage chute, 10 - output of drainage chute, 11 input of water filter, 12 - water filter, 13 - output of water filter, 14 - input of water pump, 15 - water pump, 16 - output of water pump, 17 - return tube.

Fig. 1. The scheme of the device "Recirculator of ventilated air" (RVA).

After the mechanical cleaning in air filter the recirculating air is then disinfected by the bactericidal UV lamps and then additionally disinfected in the hydraulic camera by the solution of neutral anolyte (an ecologically pure electrochemically activated disinfectant). The active ingredients of this disinfectant are not xenobiotics and do not detrimentally impact the health of animals and human [12]. The aerosol-grade spraying of the disinfectant (particle size 10-50 $\mu \mathrm{m}$ ) via the spraying nozzles in the air to disinfect (so-called "air washing”) is the ultimate stage of the removal of dispersed dust particles and/or microorganisms from the recirculating air. The cleaned and moistened air is then leaving the device and entering the poultry house.

The counter of air humidity mounted in the poultry house automatically switches off the spraying nozzles in cases of excessively high level of air humidity.

The condensed spent anolyte via drainage chute enters the water filter for the removal of the previously captured air pollutants and then moves back to hydraulic collector by the water pump. The hydraulic collector provides the even distribution of the cleaned anolyte between the spraying nozzles. 


\section{The results}

In Trial 1 the upper-room disinfection of the air within the populated poultry house resulted in the decrease in total microbial count after 2 weeks of the disinfection by $60-70 \%$ in compare to control; after 4 weeks the efficiency of UV irradiation decreased to $40-50 \%$.

At 21 days of broilers' age (3 weeks of disinfection) concentration of $E$. coli in the air decreased by $90-100 \%$ in compare to control. Since lethal dose (LD) of UV irradiation for this bacterial species is equal to the LDs for certain pathogenic viruses it can be assumed that the regime of UV irradiation used in Trial 1 can significantly decrease the risks of certain airborne viral diseases in broilers. The positive effects of the UV irradiation of the air on the productive performance in broilers was found: average live bodyweight at slaughter was higher by $7.0 \%$, mortality rate lower by $0.9 \%$, feed conversion ratio lower by $2.4 \%$, European production efficiency factor (EPEF) higher by 34 points in compare to control. No negative effects of UV on the visual ability in broilers were found.

A possible negative impact of the UV irradiation on the farm personnel could be avoided by the magnetic contact detectors set on the doors of the rooms with irradiators: opening of a door by an entering person will interrupt the control chain switching-on the locking relay and switching-off the UV irradiators. When leaving the room the person should press the special button re-running the irradiator [13].

The test of the RVA device (Trial 2) in the populated poultry house revealed the decreases in the total microbial count in the air by $75.1-87.4 \%$ in compare to control. The efficiency of elimination of coliforms, Staphylococci, and fungi was 99.16-99.86\%.

These improvements, in turn, improved the productive performance in broilers: the increase in average live bodyweight at slaughter by $13.7 \%$ and decrease in mortality level by $2.2 \%$ in compare to control were found.

\section{Conclusions}

The disinfection of air in populated poultry houses for floor-housed broilers by a bactericidal UV irradiation using upper-room method or by closed UV irradiation using the developed RVA device significantly decreased total microbial counts in the air without any detrimental effects on the visual ability of the birds and positively affected the productive performance.

The use of modern UV equipment for air disinfection in the populated poultry houses can significantly improve the efficacy of any program of the prevention of airborne diseases in poultry and decrease the negative environmental impact of the poultry producing farms.

\section{References}

1. O.R. Ilyasov, O.P. Neverova, G.V. Zueva, P.V. Sharavyev, Bull. South Ural State Univ., Ser. Food Biotechnol. 5, 59-65 (2017)

2. B. Bakutis, E. Monstviliene, G. Januskeviciene, Acta Vet. Brno. 73: 283-289 (2004)

3. K. Plewa, E. Lonc, Polish J. Environ. Stud. 20, 725-731 (2011)

4. K. Radon, B. Danuser, M. Iversen, E. Monso, C. Weber, J. Hartung, K. Donham, U. Palmgren, D. Nowak, Ann. Agric. Environ. Med. 9, 41-48 (2002)

5. E. Lonc, K. Plewa, Polish J. Environ. Stud. 19, 15-19 (2010)

6. K. Roque, G.-D. Lim, Ji-H. Jo, K.-M. Shin, E.-S. Song, R. Gautam, Ch.-Y. Kim, K. Lee, S. Shin, H.-S. Yoo, Y. Heo, H.-Ah Kim, J. Vet. Sci. 4, 531-538 (2016)

7. K. Brodka, A. Kozajda, A. Buczynska, I. Szadkowska-Stanczyk, Intl. J. Occup. Med. 
Environ. Health. 25, 281-293 (2012)

8. H.N. Chinivasagam, T. Tran, L. Maddock, A. Gale, P.J. Blackall, Appl. Environ. Microbiol. 75, 7417-7425 (2009)

9. G. Kostadinova, G. Petkov, S. Denev, Ch. Miteva, R. Stefanova T. Penev, Bulgar. J. Agric. Sci. 20, 56-65 (2014)

10. P. Millner, Bioresour. Technol. 100, 5379-5385 (2009)

11. I.P. Saleeva, A.V. Ivanov, V.G. Shol, N.A. Koroleva, V.A. Ofitserov, Ptitsevodstvo. No 9, 49-52 (2016)

12. I.P. Saleeva, E.V. Zhuravchuk, A.A. Zaremskaya, .V. Ivanov, V.Yu. Morozov, Vestnik APK Stavropolya. No 4, 50-54 (2018)

13. L.Yu. Yuferev, D.A. Baranov, A.A. Mikhalev, Mechan. Electrific. Agric., No 2, 19-21 (2012) 